The merest pinch of sugar will suffice to reduce a very abundant precipitate of manganese peroxide if the boiling be continued for some time after its addition to the liquid.

For the filtration of the yellow phosphomolybdate precipitate with the aid of the pump, it is the writer's experience that nothing succeeds so well as two seven cm. Schleicher \& Schüll No. 579 filter papers, folded and placed in the funnel together. The filtration may be made very rapidly, yet without any of the precipitate going through the paper.

After the solution of the yellow precipitate on the filter paper in ammonia and washing, the same filter may be used (without removal from the funnel) for another phosphomolybdate filtration, and so on for a number of consecutive determinations.

No. 579 is a very loose and porous paper. No. 589 black rib. bon also serves.

\title{
SOME NEW COMPOUNDS OF THALLIUM.
}

By L. M. Dennis and Martha DoAN, with Crystallographic Notes, by A. C. Gill. Rereived September 4 , 1896.

THALIOUS TRINITRIDE, TIN .

$\bigvee^{\mathrm{HEN}}$ a concentrated solution of potassium trinitride containing a little free hydronitric acid is added to a solution of thallous sulphate, a white, finely crystalline precipitate is formed. This compound is soluble in hot water, and when recrystallized from a hot aqueous solution, it separates in orthorhombic needles of a light straw color.

The thallium in this salt was determined volumetrically by means of a standard solution of potassium permanganate, according to the method of Willm. ${ }^{1}$

In the case of the hydronitric acid, a volumetric method also was first attempted. A weighed portion of the salt was dissolved in water and placed in a Hempel distilling bulb, which was connected by fused joints to a condenser. A separatory funnel was inserted in the neck of the distilling bulb. The hydronitric acid was set free by the addition of an excess of dilute sulphuric acid and was distilled into an Erlenmeyer flask containing a known amount of ammonia, the excess of ammonia being then deter- 
mined by titration. It was at first difficult to drive over all of the hydronitric acid, the results being uniformly low with one exception, and in that case the distillate gave a reaction for sulphuric acid. The results continued poor in spite of various modifications which were tried, so that finally recourse was had to the gravimetric method, this not having been used before because of the explosive character of the silver trinitride. A weighed portion of the salt was dissolved in water and precipitated with a neutral silver nitrate solution. The silver trinitride was thoroughly washed by decantation with cold water, the washings being passed through a Schleicher and Schuill hardened filter No. 575. The precipitate was then transferred to the paper, the point of the filter carefully perforated and the precipitate washed through into a weighed porcelain crucible. Hydrochloric acid was then added to the contents of the crucible and the whole evaporated to dryness. By this treatment the silver trinitride is decomposed and the hydronitric acid expelled, together with the excess of hydrochloric acid. The silver chloride remaining in the crucible was then weighed, and from its weight the amount of nitrogen in the salt was computed. The results were:

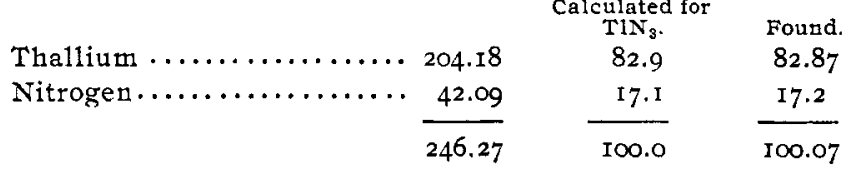

The prism angle could be measured on the goniometer, but the end faces were too small to give good reflections. The trace of the macrodome on the prism face was measured repeatedly on the microscope stage, giving an angle of $5 \mathrm{I}^{\circ} 3 \mathrm{O}^{\prime}$ with the vertical edge. The prism angle, IIO : IIO $=79^{\circ} 50^{\prime}$. Hence the axial ratio :

$$
\text { a }: \bar{b}: c^{\prime}=0.8366: \mathbf{I}: \text { I. } 2407 \text {. }
$$

The crystals were composed of many fine needles, sometimes twinned on the prism face ( I IO), but more frequently in parallel growth. The double refraction was strong, and the plane of the optical axes is at right angles to the long direction of the needles, $i . e_{.},=0.00 \mathrm{I}$. 
Thallous trinitride is somewhat soluble in cold water and is easily soluble in hot water. It is not explosive, resembling in this particular the trinitrides of potassium and sodium. It melts without decomposition when heated in an atmosphere of carbon dioxide. Its melting point was determined by placing some of the crystals in a small glass tube in the top of which was inserted a cork with two holes. Carbon dioxide was passed into the tube through one of these openings, and a small exit tube was inserted in the other. The tube was heated by immersing it in a bath containing an easily fusible alloy, and the temperature was measured with a carbon dioxide filled thermometer corrected by the Physikalisch-Technische Reichsanstalt of Charlottenburg. The corrected temperature at which the crystals melted was $334^{\circ}$.

When exposed to the sunlight, the crystals of thallous trinitride assume a dark brown appearance, which is probably due to the formation of thallous oxide. This change must be very superficial, however, as no change in weight could be detected in a sample which had been in a southern exposture for two months.

When heated in a current of dry nitrogen, thallous trinitride was easily reduced. The hydrogen on leaving the combustion tube, in which the boat containing the thallous trinitride was placed, was passed through two bulbs containing water. The aqueous solution thus obtained had a very distinct odor of ammonia, turned turmeric paper brown, and when neutralized with hydrochloric acid and allowed to spontaneously evaporate over sulphuric acid and caustic potash, it yielded crystals which under the microscope were identical with those of ammonium chloride. The ammonia found in two of the reductions in hydrogen was titrated with standard acetic acid, this acid being used in order that only the free ammonia might be neutralized and any ammonia which might be present combined with hydronitric acid would remain as such.'

In one case 29.83 per cent. of the nitrogen in the trinitride acid was converted into ammonia; in the other 27.37 per cent. of the nitrogen was thus changed.

$1 \mathrm{HX}_{\mathrm{g}}$ is somewhat stronger than glacial acetic acid. J.prakt. Chem.. (2), 43, 207 . 
Hydronitric acid was tested for in the aqueous solution by addition of silver nitrate to the solution in which the ammonia had been neutralized, and in each case only a trace was found. It was thought that perhaps the formation of the acid might be due to the presence of a small amount of moisture in the hydrogen, so a reduction was made with hydrogen which had been passed through a piece of moist cotton. In this case $2 \mathrm{I} .55$ per cent. of the nitrogen was converted into ammonia, and as before only a small amount of hydronitric acid was formed.

The highest results for the nitrogen converted into ammonia approximate one-third of the total nitrogen present, and inasmuch as only a trace of the nitrogen is found to exist in the form of hydronitric acid, it is possible that the molecule of the acid breaks down thus :

$$
\underset{\mathrm{N}}{\mathrm{N}} \backslash \mathrm{N}-\mathrm{H}+\underset{\mathrm{H}}{\mathrm{H}}=\mathrm{N}_{2}+\mathrm{N} \underset{\backslash \mathrm{H}}{\stackrel{\mathrm{H}}{-}} .
$$

THALLOUS THALIIC TRINITRIDE, TIN ${ }_{3} \cdot$ TIN $_{8}$.

It was thought that thallic trinitride might be obtained by the solution of freshly precipitated thallic hydroxide in hydronitric acid. The hydroxide when treated with hydronitric acid and warmed, dissolved to a clear straw-colored solution, but when the solution was allowed to stand at ordinary temperature, hydronitric acid escaped and thallic hydroxide was precipitated. Concentration of the solution was tried by placing it in a freezing mixture and removing the water as ice. From the liquid thus concentrated, bright yellow crystals separated, yet so much of the salt solution was occluded in the ice that this method proved wasteful. The best yield of crystals was obtained by dissolving the thallic hydroxide in a one and six-tenths per cent. solution of hydronitric acid and allowing the solution to stand at a temperature of about zero in a Hempel desiccator which was exhausted by means of a common suction pump. Glistening, yellow, needle-shaped crystals appeared. They were removed in five fractions, which under the microscope seemed to be alike and homogeneous.

1 The further investigation of this reaction is now being carried on in this labora. tory. D 
These sharply outlined crystals verged toward a brown color in the larger specimens. On the stage of a microscope they showed either parallel extinction, or an extinction of $42^{\circ}$. That is, the long direction of the crystals varied in different individuals. The crystals were probably triclinic, though there is a possibility that they furnished a case of flattening, parallel to the face of the orthorhombic pyramid. An optical axis emerged obliquely from the tabular face, showing that it was not really, as would otherwise appear, the pinacoid of an orthorhombic crysta1. The plain angles were $132^{\circ}, 132^{\circ}$ and $96^{\circ}$. The double refraction was not very strong.

The thallium was determined by dissolving some of the crystals in dilute hydrochloric acid, reducing the thallium to the thallous condition by sulphurous acid, driving of the excess of the latter acid by heating the solution and then titrating with potassium permanganate. The nitrogen could not be determined by the method used for thallous trinitride, because the salt could not be dissolved either in water or dilute acids without evolution of hydronitric acid. For this reason the absolute method was used. We had already found that the salt was highly explosive, but the behavior of the thallous trinitride, when heated in an atmosphere of carbon dioxide, led us to attempt the decomposition of a small portion of this substance in a similar manner. A few milligrams were, accordingly, spread over the bottom of a long porcelain boat, which was placed in a combustion tube containing granular copper oxide. The tube was connected at one end to a carbon dioxide generator, and at the other to a Schiff nitrometer. The exit end of the tube was heated to redness and the heat was then run back very carefully toward the boat. Gradual decomposition of the compound, however, was not attained, for when the temperature in the neighborhood of the boat had risen but slightly, the salt exploded violently, shattering the boat and tube. Another portion of the hydronitride was then mixed with granular copper oxide and heated as before. The decomposition in this case was quiet and gradual. The nitrogen in the nitrometer amounted to 27.32 per cent. of the salt taken. It seemed possible, however, that in mixing the hydronitride with the coarse copper oxide, some of the salt 
might have been decomposed by the friction, and that consequently the above per cent. of nitrogen might be too low. To ascertain if this were true, a fresh portion of copper oxide was ground very fine and was then carefully mixed with a small portion of the salt. In this way higher results were obtained.

The analysis gave:

\begin{tabular}{|c|c|c|c|}
\hline Thallium $\ldots \ldots \ldots \ldots \ldots$ & 204.18 & $\begin{array}{c}\text { Calculated for } \\
\mathrm{T}_{\mathrm{j}} \mathrm{N}_{8} \text {. } \\
70.8 \mathrm{I}\end{array}$ & $\begin{array}{r}\text { Found. } \\
70.70\end{array}$ \\
\hline 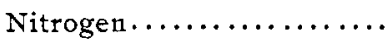 & 84.18 & 29.19 & $29 \cdot 3$ \\
\hline & 288.36 & 100.00 & 100.00 \\
\hline
\end{tabular}

If this were a simple compound, the thallium would seem to be in the bivalent condition, but as this is at variance with the usual behavior of the element, it seemed more probable that the compound is a double salt containing thallium in both the thallous and thallic condition. This supposition was confirmed by the behavior of the crystals when treated with hot water. Brown thallic hydroxide separated, and upon filtering this off and adding potassium iodide to the filtrate, a precipitate of thallous iodide resulted. Instead, however, of finding only fifty per cent. of thallium in the thallous condition, as would be required by the formula $T 1 N_{3}$. $T 1 N_{8}$, there was obtained 63.7 per cent. This excess of thallous thallium is doubtless due to the reduction of some of the thallic hydroxide by the hydronitric acid set free when the salt is treated with hot water.

Thallous-thallic trinitride is highly explosive, the decomposition being accomplished by a sharp report and a vivid flash of green light. The explosion can be brought about by heat, percussion or even gentle friction.

THALLOUS TELLURATE, $\mathrm{T}_{2} \mathrm{TeO}_{4}$.

In $1878 \mathrm{~F}$. W. Clarke prepared what he supposed to be thallous tellurate by precipitating a thallous nitrate solution with ammonium tellurate. ${ }^{\prime}$ The amount obtained was so small that no analysis was made.

To avoid the presence of other salts in the solution, we used a solution of thallous hydroxide and precipitated that by adding a

1 Ber, d. chem. Ges., I1, 1507 . 
solution of pure telluric acid. The white, flocculent precipitate which formed was washed with cold water, transferred to a filter and dried over calcium chloride.

In the analysis of this substance, the thallium was determined by the method above described. Considerable difficulty was encountered in the determination of the tellurium, the presence of thallium making it impossible to use either the potassium permanganate titration or the method recently described by Gooch.' The thallous tellurate was soluble in water, but the amount of water required for its solution was so great that the telluric acid could be precipitated by neither lead nor barium solutions. For these reasons the method of $\mathrm{Kastner}^{2}$ was used, the tellurium being precipitated in alkaline solution by means of grape sugar. As some thallium separated with the tellurium, the precipitate was treated with nitric acid and the acid then driven off by evaporation. The thallous nitrate was removed by washing the residue with water and the tellurous oxide was filtered in a Gooch crucible, dried and weighed. The results were:

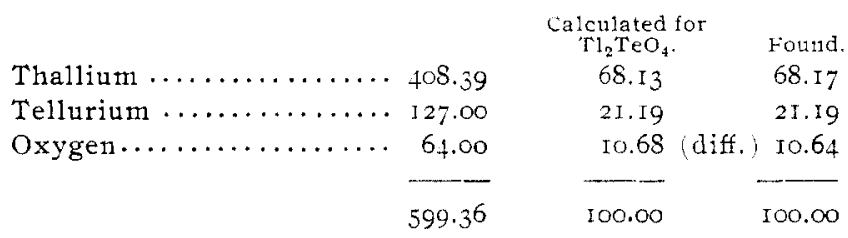

Thallous tellurate is slightly soluble in water, and it was hoped that there might be obtained from the aqueous solution crystals sufficiently well defined to admit of a comparison of them with those of thallous sulphate and thallous selenate. Unfortunately, however, it was found impossible, in spite of many and varied attempts, to obtain anything but a white amorphous powder. Even when a solution saturated at $40^{\circ}$ was allowed to slowly cool to $15^{\circ}$ through a period of eight days, no crystals resulted.

THALLOUS CYANPLATINITE, $\mathrm{Tl}_{2} \mathrm{Pt}(\mathrm{CN})_{4}$.

Carstanjen prepared what he reported to be thallous cyanplat-

1 Ztschr. anorg. Chem., 7, 132.
2 Ztschr. anal. Chem., 14, 142. 
inite by neutralizing cyanplatinous acid with thallous carbonate. ${ }^{1}$ The compound was given the formula TICN.PtCN, although no analytical results were given.

The cyanplatinous acid used by us in the preparation of the thallium cyanplatinite was obtained according to the method of Schafarik." It was neutralized by thallous hydroxide, which was prepared by precipitating a thallous sulphate solution with the calculated amount of baryta water. The crystals separated out in the form of thin plates.

A determination of the thallium and cyanogen gave the following results :

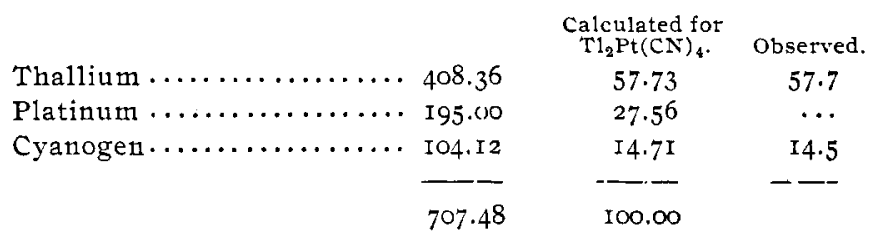

The crystals are nearly colorless plates, usually very thin and occurring irregularly grown together on the flat sides. The crystal system was not positively determinable from the material at hand, but is probably triclinic, possibly monoclinic with crossed dispersion. In converged polarized light, a bisectrix is seen nearly or quite normal to the large face of the plates, and the dispersion of the planes of the optic axes is remarkably strong, so that the crystals simply change color without becoming dark on rotation between crossed Nicols. The double refraction is high. The plates are bounded by crystal faces, giving them a six-sided outline, but on the material used no goniometric measurements could be made.

CORNELL UNIVERSTT,

ACGUST 1896 .

1 I. prakt. Chem.. I02, I 44 .

2 Ibid. .66, 40 r. 